\title{
Correction to: A nanoemulsion/micelles mixed nanosystem for the oral administration of hydrophobically modified insulin
}

\author{
Irene Santalices ${ }^{1,2} \cdot$ Carlos Vázquez-Vázquez $^{3} \cdot$ Manuel J. Santander-Ortega ${ }^{4,5} \cdot$ Victoria Lozano ${ }^{4,5}$. \\ Francisca Araújo ${ }^{6} \cdot$ Bruno Sarmento $^{6,7} \cdot$ Neha Shrestha $^{8} \cdot$ Veronique Préat $^{8} \cdot$ Miguel Chenlo $^{9} \cdot$ Clara V. Alvarez $^{9}$. \\ Federico Benetti ${ }^{10}$. Juan Cuñarro ${ }^{1}$. Sulay Tovar $^{1}$. Dolores Torres ${ }^{2}$. María José Alonso ${ }^{1,2}$
}

Published online: 19 March 2021

(c) The Author(s) 2021

\section{Correction to: Drug Delivery and Translational Research https://doi.org/10.1007/s13346-021-00920-x}

The article A nanoemulsion/micelles mixed nanosystem for the oral administration of hydrophobically modified insulin, written by Santalices et al., was originally published electronically on the publisher's internet portal on February 11, 2021, without open access. With the authors' decision to opt for Open Choice the copyright of the article changed on February 25,2021 , to $\odot$ The Author(s) and the article is forthwith distributed under a Creative Commons Attribution 4.0 International License.
Open Access This article is licensed under a Creative Commons Attribution 4.0 International License, which permits use, sharing, adaptation, distribution and reproduction in any medium or format, as long as you give appropriate credit to the original author(s) and the source, provide a link to the Creative Commons licence, and indicate if changes were made. The images or other third party material in this article are included in the article's Creative Commons licence, unless indicated otherwise in a credit line to the material. If material is not included in the article's Creative Commons licence and your intended use is not permitted by statutory regulation or exceeds the permitted use, you will need to obtain permission directly from the copyright holder. To view a copy of this licence, visit http://creativecommons.org/licenses/by/4.0/.

Publisher's Note Springer Nature remains neutral with regard to jurisdictional claims in published maps and institutional affiliations.
The original article can be found online at https://doi.org/10.1007/ s13346-021-00920-x.

María José Alonso

mariaj.alonso@usc.es

1 Center for Research in Molecular Medicine and Chronic Diseases (CIMUS), University of Santiago de Compostela, Campus Vida, 15782 Santiago de Compostela, Spain

2 Department of Pharmaceutics and Pharmaceutical Technology, School of Pharmacy, University of Santiago de Compostela, Campus Vida, 15782 Santiago de Compostela, Spain

3 Department of Physical Chemistry, Faculty of Chemistry, University of Santiago de Compostela, Campus Vida, 15782 Santiago de Compostela, Spain

4 Cellular Neuroanatomy and Molecular Chemistry of Central Nervous System Group, School of Pharmacy, University of Castilla-La Mancha, 02071 Albacete, Spain

5 Regional Centre of Biomedical Research (CRIB), University of Castilla-La Mancha, 02071 Albacete, Spain
6 Instituto de Investigação E Inovação Em Saúde (i3S), Instituto Nacional de Engenharia Biomédica (INEB), Universidade Do Porto, Rua Alfredo Allen 208, 4200-135 Porto, Portugal

7 Instituto de Investigacão E Formacão Avançada Em Ciências E Tecnologias da Saúde (CESPU), 4585-116 Gandra, Portugal

8 Advanced Drug Delivery and Biomaterials, Université Catholique de Louvain, Louvain Drug Research Institute, 1200 Brussels, Belgium

9 Neoplasia \& Endocrine Differentiation Group, Center for Research in Molecular Medicine and Chronic Diseases (CIMUS), University of Santiago de Compostela, Campus Vida15782, Santiago de Compostela, Spain

10 ECSIN-European Center for the Sustainable Impact of Nanotechnology, ECAMRICERT SRL, Padova, Italy 